\title{
The Evolutionary Origins of Southeast Asian Ovalocytosis
}

\author{
A.M. Paquette ${ }^{1}$
}

A. Harahap ${ }^{2}$

V. Laosombat ${ }^{3}$

J.M. Patnode ${ }^{1}$

A. Satyagraha ${ }^{2}$

H. Sudoyo ${ }^{2}$

M.K. Thompson ${ }^{1}$

N. M. Yusoff ${ }^{4}$

J.A. Wilder ${ }^{1 *}$

${ }^{1}$ Department of Biological Sciences, Northern Arizona University, Flagstaff, AZ USA 86011

${ }^{2}$ Eijkman Institute for Molecular Biology, Jakarta, Indonesia

${ }^{3}$ Division of Pediatric Hematology \& Oncology, Faculty of Medicine, Prince of Songkla University, Hat Yai, Songkla 90110, Thailand

${ }^{4}$ Advanced Medical and Dental Institute, Universiti Sains Malaysia, 13200 Kepala Batas, Pulau Pinang, Malaysia

*Author for Correspondence: Jason A. Wilder; jason.wilder@nau.edu 


\section{Abstract}

Southeast Asian Ovalocytosis (SAO) is a common red blood cell disorder that is maintained as a balanced polymorphism in human populations. In individuals heterozygous for the SAO-causing mutation there are minimal detrimental effects and well-documented protection from severe malaria caused by Plasmodium vivax and $P$. falciparum; however, the SAO-causing mutation is fully lethal in utero when homozygous. The present-day high frequency of SAO in Island Southeast Asia indicates the trait is maintained by strong heterozygote advantage. Our study elucidates the evolutionary origin of SAO by characterizing DNA sequence variation in a 9.5 kilobase region surrounding the causal mutation in the $S L C 4 A 1$ gene. We find substantial haplotype diversity among SAO chromosomes and estimate the age of the trait to be approximately 10,005 years ( $95 \% \mathrm{Cl}: 4,930-23,200$ years). This date is far older than any other human malaria-resistance trait examined previously in Southeast Asia, and considerably pre-dates the widespread adoption of agriculture associated with the spread of speakers of Austronesian languages some 4,000 years ago. Using a genealogy-based method we find no evidence of historical positive selection acting on SAO $(s=0.0,95 \% \mathrm{Cl}: 0.0-0.03)$, in sharp contrast to the strong present-day selection coefficient (e.g., 0.09) estimated from the frequency of this recessively lethal trait. This discrepancy may be due to a recent increase in malaria-driven selection pressure following the spread of agriculture, with SAO targeted as a standing variant by positive selection in malarial populations.

Keywords: ovalocytosis, SLC4A1, malaria, soft sweep 


\section{Introduction}

Southeast Asian Ovalocytosis (SAO) is a human red blood cell deformity that confers broad-spectrum protection against multiple malaria-causing parasites and represents a canonical example of balancing selection operating via heterozygote advantage in humans. The trait is caused by a 27 base-pair deletion in SLC4A1, the gene encoding the erythrocyte membrane Band 3 protein (Jarolim et al., 1991). SAO is associated with heterozygous carriers of the deletion, and when homozygous the mutation is fully lethal in utero in the absence of extraordinary medical intervention (Genton et al., 1995; Liu et al., 1994; Picard et al., 2014). Evidence for a heterozygote advantage for individuals with SAO in malarial areas comes from case-control studies that have demonstrated nearly complete protection conferred by SAO against severe clinical malaria (including cerebral malaria) and malaria-related mortality caused by Plasmodium falciparum (Allen et al., 1999; Genton et al., 1995; Rosanas-Urgell et al., 2012). This protection may be due to altered cytoadherence properties of infected SAO red blood cells that make cerebral sequestration and associated death less likely (Cortés et al., 2005). Additionally, in a study of children in Papua New Guinea the trait was shown to protect against $P$. vivax parasitemia, infection prevalence, and incidence of severe malarial disease (Rosanas-Urgell et al., 2012). These results suggest that SAO provides a broad spectrum of defense against disease caused by multiple Plasmodium species. Further evidence of the role of malaria-driven natural selection acting to maintain the trait comes from a positive correlation between SAO frequency and endemicity of $P$. falciparum in Island Southeast Asia and Melanesia (Mgone et al., 1996). Indeed, based on its high 
frequency, a fitness advantage of approximately $9 \%$ has been estimated for individuals with SAO in strongly malarial areas of Papua New Guinea (Genton et al., 1995).

SAO is widespread in Island Southeast Asia and neighboring regions on the Malay Peninsula as far north as southern Thailand (Kimura et al., 1998; Kimura et al., 2003; Mgone et al., 1996; Ngouprommin et al., 2012). Individuals with SAO are characterized as having oval-shaped red blood cells with increased membrane rigidity and decreased anion transport, but no clinical symptoms beyond sporadic associations with anemia in both adults and neonates (Amato and Booth, 1977; Coetzer et al., 1996; Laosombat et al., 2005; Laosombat et al., 2010; O'Donnell et al., 1998; Reardon et al., 1993; Schofield et al., 1992). The deletion mutation that causes SAO removes 9 amino acids from within the $11^{\text {th }}$ exon of SLC4A1 and distinguishes SAO from other forms of ovalocytosis in Southeast Asia (Kimura et al., 2006; Patel et al., 2001).

While the protective effects of SAO against malaria are well established, the evolutionary history of this trait is poorly understood. Although it is most common in Island Southeast Asia, it has also been found at low frequency in widely dispersed locations, including Madagascar, Mauritius, South Africa and Sri Lanka (Coetzer et al., 1996; Rabe et al., 2002; Tanner et al., 1991; Vidyatilake and Gooneratne, 2004). One explanation for this pattern is that the trait originated in Island Southeast Asia and then spread across the Indian Ocean via dispersal of speakers of Austronesian languages (Rabe et al., 2002). Austronesian settlement of Madagascar is estimated to have occurred approximately 1,200 years ago and originated in the Java-KalimantanSulawesi area (Cox et al., 2012; Pierron et al., 2014), suggesting the trait was present in the Austronesian source population at this time. In communities of Papua New Guinea 
associations between SAO frequency and Austronesian language have been demonstrated, again suggesting a link between the spread of Austronesian-speaking individuals and the distribution of SAO (Kimura et al., 2003; Tsukahara et al., 2006). However, while many uniquely Austronesian genetic markers have affinities with present-day aboriginal Taiwanese, this pattern is not observed for SAO (Wilder et al., 2009). This discrepancy suggests that the association between SAO and speakers of Austronesian-languages developed only in the later dispersal stages of the Austronesian expansion. As such, the origins of SAO remain unclear and it is not known how long populations in Southeast Asia have possessed this trait.

This study elucidates the origins of SAO as well as the historical selection coefficient affecting the trait by examining patterns of nucleotide diversity and linkage disequilibrium among chromosomes bearing the causal mutation from across its geographical range. Island Southeast Asia harbors a diversity of unique alleles that confer resistance to malarial disease, but few have been examined from an evolutionary perspective. The case of SAO is particularly intriguing, as it represents an outstanding example of a rare balanced polymorphism in humans.

\section{Materials and Methods}

\subsection{DNA Samples and Amplification}

We examined a total of $60 \mathrm{SAO}$ chromosomes, sampled from four geographically disparate sources: Southern Thai individuals sampled in Thailand $(n=18)$; one selfidentified Chinese and five self-identified Malays sampled in Malaysia $(n=6)$; and individuals of diverse indigenous Indonesian ancestry from the provinces of North 
Maluku ( $n=19)$ and East Nusa Tenggara, Indonesia $(n=18)$. All individuals included in this study were confirmed by diagnostic DNA amplification to be from heterozygous carriers of the SAO-causing mutation. It is important to note that the resulting sample of chromosomes is not a randomly chosen representation of the population; instead we have over-sampled chromosomes bearing the SAO-causing mutation to better estimate variability among SAO chromosomes and test hypotheses regarding the origins of the trait. All samples were obtained using appropriate and ethical informed consent procedures and review by the institutions of origin.

The SLC4A1 gene region (17q21.31) was amplified in two steps from each of our samples. First, primers amplifying both SAO and non-SAO chromosomes (i.e., a diploid amplification) were used to generate template for direct Sanger sequencing of a 9,472 bp region centered approximately on the SAO mutation. Second, bi-directional allelespecific primers (placed within the 27-bp SAO-causing mutation) were used to generate allele-specific template DNA representing only the non-SAO bearing chromosome from each sample. This second round of data was used to infer the phase of all of the variants identified in our sample, and to identify unambiguously the haplotypes associated with each SAO chromosome. When possible, we corroborated rare SAO haplotypes using alternative SNP-typing methodologies (e.g., PCR-RFLP analyses), and verified all singleton sites through multiple rounds of DNA amplification and sequencing. All primers and reaction conditions used for these procedures are available upon request. For our Malaysian samples $(n=6)$, limited template DNA quantity allowed us to amplify only 8,029 bp in our diploid amplifications (1,443 bp shorter than all other samples). The region of SLC4A1 missing in these Malaysian samples is invariant in the 
remainder of the sample set, and also is invariant in the allele-specific amplification of non-SAO bearing chromosomes from the Malaysian samples. As such, it is formally possible, albeit unlikely, that we have failed to detect existing variation in this region of the six sampled SAO chromosomes from Malaysia.

\subsection{Data Analysis}

Analyses of polymorphism were carried out using the program DNAsp v.5.1 (Librado and Rozas, 2009). Diversity statistics reported here include the number of segregating sites, $S$; average number of pairwise differences among sequences, $\pi$ (Nei and $\mathrm{Li}$, 1979); Watterson's (1975) theta, $\theta_{w}$; and haplotype diversity, $\mathrm{Hd}(\mathrm{Nei}, 1987)$. The minimum number of recombination events $\left(R_{m}\right)$ was calculated following Hudson and Kaplan (1985). A haplotype network was constructed using the median-joining algorithm implemented in NETWORK v.4.6 (fluxus-engineering.com) and was re-drawn for clarity (Bandelt et al., 1999). All unique-event polymorphisms, including both base substitutions and indels, were considered in our analyses. Tests of selection incorporated here included Tajima's D (Tajima, 1989), Fu and Li's D* (Fu and Li, 1993), and Fay an Wu's H (Fay and Wu, 2000). These tests of selection that utilize the frequency spectrum of mutations require a random sample of chromosomes, rather than a sample enriched for SAO chromosomes we have assembled here. To circumvent this issue we subsampled four randomly chosen SAO chromosomes and considered these together with the 60 non-SAO chromosomes as a quasi-random constructed sample. We evaluated the tests of selection for departures from neutral expectations using coalescent simulations carried out in DNAsp v.5.1 (Librado and Rozas, 2009) and 
conditioned on the observed value of $\theta_{W}$ for the quasi-random sample. For all analyses requiring an outgroup, a publicly available sequence from Gorilla gorilla (gorGor3 assembly) was used (available data from Pan troglodytes contained numerous gaps in the SLC4A1 region and was therefore less suitable for use in this study). Archaic hominin (Neanderthal and Denisovan) SLC4A1 sequence was downloaded from the UCSC Genome Browser, and represents data from (Green et al., 2010) and (Reich et al., 2010), respectively.

As an initial point estimate of the age of the SAO allele $(t)$, we used a simple method based on the decay of linkage disequilibrium (LD) between SNPs linked to the SAO mutation, as described by Risch et al (1995) and clarified by (Colombo, 2000). This approach estimates allele age using the frequency of a SNP allele on SAO and wildtype chromosomes together with an estimate of the recombination rate, thus it is not sensitive to assumptions regarding the frequency of SAO in the population. We used two SNPs in this analysis, representing the two nearest substitution mutations on either side of the SAO deletion (rs2857082 and rs45530735, see Figure 1). Because recombination events on either side of the mutation of interest (referred to as telomeric and centromeric sides in this work) are independent of one another, age estimates can be compared from the chromosomal regions on either side of the SAO deletion. The fine-scale genetic maps of Meyers et al. (2005) and Kong et al. (2010) indicate average recombination rates of $4.52 \mathrm{cM} / \mathrm{Mb}$ and $5.26 \mathrm{cM} / \mathrm{Mb}$, respectively over the area resequenced in this study; hence, and all analyses here used $5.0 \mathrm{cM} / \mathrm{Mb}$ as an estimate of the local recombination rate unless otherwise noted. 
Additionally, we used the Bayesian approach of Slatkin (2008) to estimate the selection coefficient $(s)$ characterizing the SAO mutation, and also as a second method to estimate the age of SAO (complementing the Risch et al. method described above). This approach estimates parameters of interest based on the frequency of recombinant haplotypes between SAO and multiple linked markers on either side of the SAO mutation. For this analysis, we assumed a present-day regional effective population size of $10^{5}$ based on estimates for Island Southeast Asia obtained by Guillot et al. (2013), an exponential growth parameter of 0.0065 , and a frequency of SAO of 0.05 . This method is sensitive to assumed rates of growth, but much less so to assumptions regarding allele frequency or population size (Slatkin 2008).

In all analyses we assumed a generation time of 29 years in the interpretation of our results, based on the work of Fenner (2005). This value represents the overall human generation interval (i.e., male and female) and takes into account the typically longer male generation time, as is appropriate for an autosomal genetic locus.

\section{Results}

\subsection{Nucleotide Variation}

We successfully resequenced and experimentally phased a 9,472 base-pair portion of the SLC4A1 gene in 60 SAO heterozygotes from Southeast Asia, spanning Thailand to eastern Indonesia. Our phased DNA sequence data uncovered a total of 31 separate haplotypes, including 5 among SAO chromosomes and 26 from non-SAO chromosomes (Figure 1). These haplotypes are defined by 36 unique event polymorphisms, including 33 single nucleotide polymorphisms (SNPs), 2 single-base 
indels, and the 27 bp SAO-causing deletion. Six of the SNPs that we identified are not annotated in publicly available databases.

Previous studies have found that all individuals bearing the SAO mutation also possess the rare (but ancestral) allele at a nearby non-synonymous SNP (rs5036, Lys56Glu, also referred to as the "Memphis" mutation) (Jarolim et al. 1991). In our dataset we find that the majority, but not all, of SAO chromosomes possess this rare allele at rs5036 (58 out of 60 chromosomes; haplotypes 1-4 in Figure 1). The remaining SAO haplotype, which is found only in North Maluku of eastern Indonesia, bears the more common (and derived) allele of rs5036. In addition to rs5036 and the SAO mutation, we found four missense mutations. One of these, which is present as a singleton from Malaysia, is known to be associated recessively with distal renal tubular acidosis (rs121912748).

The results of standard tests of selection based on the allele frequency spectrum are shown in Table 1. Values of Tajima's $D$ and Fu and Li's $D^{*}$ are slightly negative, but show no significant deviation from expected neutral patterns (Table 1). In contrast, Fay and Wu's $\mathrm{H}(\mathrm{FWH})$ is strongly and significantly negative. Figure 2 shows a sliding window analysis of FWH in the region analyzed here, which shows a clear minimum near the SNP rs5036, while FWH is close to zero across the remainder of the SLC4A1 survey region, including the area near the SAO mutation.

\subsection{Comparison of SAO versus non-SAO Chromosomes}

When we examine patterns of variation within our full dataset we find a much lower level of variation among SAO chromosomes compared to non-SAO 
chromosomes, as summarized in Table 1. This pattern is expected due to the relative rarity of SAO in affected populations. Interestingly, two of the segregating sites that we observed among the SAO chromosomes are invariant in the non-SAO group. One of these, rs16940582, is variable in other world populations, including Han Chinese and Japanese (dbSNP); the second SNP (chr17:42,334,442) is novel to our dataset. Levels of observed recombination are also lower for SAO than non-SAO chromosomes (again, this is expected due to the rarity of SAO chromosomes), as estimated by the minimum number of recombination events $\left(R_{m}\right)$. Among non-SAO chromosomes there is evidence of substantial recombination $\left(R_{m}=7\right)$, while there is no evidence of recombination when SAO chromosomes are compared to one another $\left(R_{m}=0\right)$. When all chromosomes are examined together an additional recombination event is evident $\left(R_{m}=8\right)$, suggesting that historical recombination events between SAO and non-SAO chromosomes are detectable in our data.

Figure 3 shows a median-joining network describing the evolutionary relationships among the haplotypes we observed in our sample. SAO chromosomes, which are over-represented in our sample relative to actual population frequencies, form a cluster that is joined to the majority of non-SAO chromosomes by a long branch, suggesting a single origin for the causal mutation. The placement of the root near a cluster of non-SAO chromosomes (and quite distant from SAO chromosomes) is estimated using publicly available gorilla sequence and the relative position of the root is shared by the estimated haplotypes for Neanderthal and Denisovans (see Ancestral, Neanderthal and Denisovan haplotypes in Figure 1 for additional comparisons). 


\subsection{Estimation of the Age of the SAO Mutation and its Selection Coefficient}

The LD-based estimator of Risch et al. (1995) indicates an age of SAO of $t=294$ generations for telomeric data ( 8,526 years) and $t=306$ generations using centromeric data $(8,874$ years). Using the Bayesian approach of Slatkin (2008) the joint posterior probability surface of $s$ and $t$ was unimodal and peaked at $s=0$ and $t=660$ generations $(19,140$ years), as shown in Figure 4A. The marginal posterior probability distribution of $s$ shows a clear peak at $s=0$, with $95 \%$ of the probability density occurring at $s<0.03$ (Figure 4B). The marginal posterior probability distribution of $t$ is shown in Figure 4C and exhibits no clear single peak, but is maximized at $t=345$ generations $(10,005$ years) with $95 \%$ of the probability density occurring between 170 and 800 generations $(4,930-23,200$ years $)$.

\section{Discussion}

The evolution of malaria resistance in human populations from Island Southeast Asia is poorly understood. Our study demonstrates that SAO is the result of a single mutation event that we estimate to have occurred between 170 and 800 generations ago $(4,930-23,200$ years bp), with point estimates from two different methods spanning a relatively narrow range from 294 to 345 generations (8,526 to 10,005 years bp). During the time since SAO arose in human populations there has been opportunity for substantial recombination between SAO and non-SAO chromosomes over short genetic distances. In addition, we found evidence for a single mutational event that occurred on one of our sampled SAO chromosomes. These processes of recombination and mutation have created multiple SAO haplotypes, at least one of which alters what 
had previously been proposed to be a perfect association between SAO and the rare allele of a nearby non-synonymous polymorphism (the "Memphis" allele of rs5036). This pattern differs considerably from the expected pattern under a model of strong and recent directional selection favoring $\mathrm{SAO}$ as a new allele, where little haplotype diversity is expected over the narrow genetic distances examined here (Kim and Stephan, 2002; Maynard Smith and Haigh, 1974; Przeworski, 2002). It is interesting that our study corroborates earlier work noting a strong excess of rare derived variants and a significantly negative value of FWH centered at the "Memphis" rs5036 locus (Wilder et al. 2009), suggesting that this site may have been the target of positive natural selection acting independently of the SAO-causing mutation.

Our estimate of the age of SAO places its origins in the Pleistocene or early Holocene, a timeframe that vastly pre-dates the much younger $\mathrm{HbE}$ allele (1.2 - $4.4 \mathrm{kya})$ and the Mahidol allele of G6PD ( 1.6 kya), which are the only other malaria resistance alleles in Southeast Asia to have their dates of origin estimated (Louicharoen et al., 2009; Ohashi et al., 2004). Indeed, even on a global scale, the age of SAO that we estimate here falls in the upper age range of any malaria-resistance allele examined in any human population to date (reviewed in Hedrick, 2012). Our estimates of the age of SAO are sensitive to assumptions regarding the demographic history of the sampled population. Here we used a 29 year generation time in our calculations (after Fenner 2005), and differences in the actual generation time will proportionately affect the estimated age in years. The results of the Bayesian estimate of age and the selection coefficient are especially sensitive to the population growth rate (Slatkin 2008), which we assumed here to be 0.0065 . Higher growth rates are associated with slightly 
younger ages, while lower growth rates are associated with older age estimates of SAO (not shown). Genetic examination of the population history of Island Southeast Asia suggests that population sizes peaked in the Pleistocene and were flat or slightly declining in the Holocene, before growing explosively in the recent past (Guillot et al. 2013). This result suggests that much of the time since SAO originated was characterized by relatively little growth, in which case it is possible that our Bayesian estimate of SAO age is an underestimate.

While the age of SAO is unusually old for a human malaria-resistance allele, the selection coefficient (point estimate of zero, with an upper bound of 0.03 ) is much weaker than that estimated for other malaria-resistance alleles (e.g., $s=0.22$ for G6PD Mahidol, $s=0.079$ for $\mathrm{HbE}$; reviewed in Hedrick 2012). Moreover, at values near zero, it is difficult to distinguish whether the selection coefficient estimated via the Slatkin (2008) method reflects positive or negative selection. As such, the conclusion we draw from our analysis is that SAO has historically acted as a near-neutral allele, and has possibly been influenced by very weak positive or negative selection. It is notable that the value we arrive at here is very different than the strong positive selection that can be estimated for SAO using simple equilibrium models that take into account the recessive lethality of the allele and its present-day frequency. This latter method has produced an estimate of $s=0.09$ for one region on Papua New Guinea (Genton et al. 1995), and the even higher frequency of SAO in areas holoendemic for $P$. falciparum suggest an even higher selection coefficient is possible in other regions today.

The discrepancy between our genealogical estimate of a low selection coefficient affecting SAO (which reflects historical selection since the origin of the allele) and the 
much higher estimates that have been inferred for present-day populations suggests that malaria-selection favoring SAO may have increased dramatically in the relatively recent past. Reconstructing the origins of SAO in the context of malarial disease in Island Southeast Asia is challenging due to the difficulties of reconstructing the histories of human Plasmodium parasites. Recent evidence suggests that $P$. vivax and $P$. falciparum (both of which cause disease that is protected against by SAO) accompanied modern humans during the initial dispersal out of Africa and Pleistocene colonization of Southeast Asia (Joy et al., 2003; Liu et al., 2014; Mu et al., 2002; Neafsey et al., 2012; Tanabe et al., 2010). Moreover, examination of human settlement patterns and vector distributions suggest that by the early Holocene conditions in Island Southeast Asia were likely conducive to maintenance of endemic malarial disease (Poolsuwan, 1995). Despite this, many lines of evidence suggest that opportunities for intense natural selection mediated by malarial disease did not occur until after the advent of agriculture, which greatly enhanced opportunities for efficient parasite transmission (reviewed in Hartl, 2004). In Island Southeast Asia widespread adoption of agriculture became prevalent in association with the expansion of Austronesian-speaking peoples some 4,000 years ago (reviewed in Donohue and Denham, 2010 and accompanying commentary). Our estimate of the age of SAO indicates that it was present in Island Southeast Asia before this time. Moreover, our genealogical estimate of a negligible selection coefficient for SAO is consistent with a long history where the allele was not associated with beneficial effects. We propose that SAO experienced a relatively extended time-frame in which it was a standing variant in populations that experienced little to no malaria-driven selection pressure. In these conditions, SAO likely acted as a 
recessive deleterious allele, with no opportunity for malaria-mediated heterozygote advantage. Because there are minimal negative clinical effects in heterozygous individuals (making it effectively neutral when rare), SAO would it have been able to persist in populations for long periods at low frequency (albeit at low frequency due to its recessive lethality). With the advent of agriculture and associated increases in disease caused by $P$. vivax and/or $P$. falciparum, the selection coefficient associated with SAO shifted to a positive value as heterozygotes enjoyed a relative fitness advantage in environments where these diseases were common. This scenario suggests that SAO has been subject to a partial "soft sweep", where adaptation to a malarial environment in Island Southeast Asia occurred via selection acting on the preexisting SAO allele.

Recent studies have suggested that adaptation to novel environments, particularly in the case of human populations, may often act via selection acting on standing variation (i.e., "soft sweeps") and a growing number of such cases has emerged in the literature (Fu and Akey, 2013; Jones et al., 2013; Peter et al., 2012; Pritchard et al., 2010). Indeed, such a model has been proposed for the Duffy negative allele, which protects against vivax-malaria and has swept to near fixation in subSaharan Africa (Przeworski et al., 2005). In the case of SAO our data are consistent with a partial soft sweep model, where SAO existed in human populations before intense malaria selection became prevalent. We note that two lines of evidence support this inference: first, that the pattern of haplotype diversity associated with SAO suggests an age that pre-dates the origins of agriculture and accompanying rises in malarial disease in Island Southeast Asia, and; second, that present-day selection coefficients 
estimated for SAO are vastly higher than the genealogical estimates we present here. Theoretical findings suggest that soft sweeps in circumstances where a currently favored allele was weakly deleterious prior to a shift in environment (as is the case for SAO in non-malarial environments) will exhibit patterns associated with weak selection and long coalescence times like those seen here (Hermisson and Pennings, 2005). Of course, SAO differs from other cases of soft sweeps because it is a recessively lethal trait, causing positive directional selection to lead to a balanced polymorphism rather than a complete selective sweep.

In conclusion, our data from SAO suggest that it predates the origin of nearly all malaria-resistance alleles that have been studied to date, and likely was the target of selection on standing variation following the advent of agriculture and associated intensification of malarial disease in Island Southeast Asia. As a region, Island Southeast Asia harbors a rich assemblage of endemic genetic variants that are hypothesized to confer protection from malarial disease, including SAO, the Gerbich negative allele of $G Y P C$, a unique Duffy negative mutation, unique G6PD deficiency mutations, and several molecular types of $\alpha$ - and $\beta$-thalassemia (reviewed in Müller et al., 2003). The extent to which other malaria resistance alleles in Island Southeast Asia reflect standing variants versus de novo mutations represents an interesting outstanding question. 


\section{Acknowledgements}

We would like to thank John Chase, Milly Chandler and Dylan Funk for assistance with data collection and members of the Wilder laboratory and two anonymous reviewers for comments on the manuscript. This study was funded by a grant from the National Science Foundation (BCS-1062258) to J.A.W., and the funding source had no role in the design or implementation of the research. 


\section{Figure Legends}

Figure 1. Table of polymorphisms for SLC4A1. Each row identifies a unique haplotype identified in this study, with the ancestral sequence (taken from G. gorilla) shown on the top row, and Denisovan and Neanderthal sequence shown below. Haplotypes associated with the SAO-causing mutation are listed 1-5, with the remainder being non-SAO haplotypes (a horizontal line separates these two groups). Blue indicates ancestral allele at a locus, and yellow derived. Each unique event polymorphism has its 'rs' identifier listed, or its position relative to human genome build hg19 for those that are not presently annotated. Asterisks indicate non-synonymous polymorphisms. Counts of each haplotype in the four study populations are shown at right. Haplotypes extending to the left of the SAO mutation are referred to as "centromeric" in the text and those to the right of SAO are "telomeric"

Figure 2. Sliding window analysis of FWH across the SLC4A1 resequenced region ( window $=\mathbf{7 5 0}$ bp, step size $=\mathbf{2 5 0}$ bp). A statistically significant dip in FWH is centered near the nonsynonymous "Memphis" variant of SLC4A1 (rs5036). The position of the SAO mutation is also indicated.

\section{Figure 3. Median-joining network describing relationships among observed} haplotypes. Red haplotypes indicate SAO-bearing chromosomes, while yellow indicates non-SAO chromosomes. The size of each circle is proportional to the number observed of each haplotype; our sampling design is such that SAO is over-represented relative to actual population frequencies. The position of the root, determined by 
comparison to G. gorilla (and shared by Neanderthal and Denisovan sequence), is shown.

Figure 4. Probability surfaces associated with SAO age and selection coefficient. The joint-probability surface of $s$ and $t$ for the SAO allele is shown in (A). Results are from $10^{7}$ replicates, with $t$ ranging from 100 to 800 generations (35 generation interval) and $s$ ranging from zero to 0.05 (interval of 0.0033 ). The marginal distributions of $s$ and $t$, computed from the joint-probability distribution, are shown in $\mathbf{B}$ and $\mathbf{C}$, respectively. 
Table 1. Diversity statistics for SAO and non-SAO chromosomes. See text for abbreviations.

\begin{tabular}{|c|c|c|c|c|}
\hline & $\underline{\mathrm{SAO}}$ & Non-SAO & All Chromosomes & Random Sample \\
\hline $\mathrm{N}$ & 60 & 60 & 120 & 64 \\
\hline$S$ & 10 & 33 & 36 & 35 \\
\hline$\pi(\%)$ & 0.007 & 0.055 & 0.092 & 0.067 \\
\hline$\theta_{W}(\%)$ & 0.027 & 0.088 & 0.084 & 0.093 \\
\hline$H d$ & 0.19 & 0.91 & 0.78 & 0.92 \\
\hline$R_{m}$ & 0 & 7 & 8 & 7 \\
\hline TD & - & - & - & -0.883 \\
\hline FLD* & - & - & - & -0.454 \\
\hline FWH & - & - & - & $-8.477^{\star}$ \\
\hline
\end{tabular}




\section{Literature Cited}

Allen, S.J., O'Donnell, A., Alexander, N.D., Mgone, C.S., Peto, T.E., Clegg, J.B., Alpers, M.P., Weatherall, D.J., 1999. Prevention of cerebral malaria in children in Papua New Guinea by southeast Asian ovalocytosis band 3. Am J Trop Med Hyg 60, 1056-1060.

Amato, D., Booth, P.B., 1977. Hereditary ovalocytosis in Melanesians. P N G Med J 20, 26-32.

Bandelt, H.J., Forster, P., Rohl, A., 1999. Median-joining networks for inferring intraspecific phylogenies. Molecular biology and evolution 16, 37-48.

Coetzer, T.L., Beeton, L., van Zyl, D., Field, S.P., Agherdien, A., Smart, E., Daniels, G.L., 1996. Southeast Asian ovalocytosis in a South African kindred with hemolytic anemia. Blood 87, 1656-1657.

Colombo, R., 2000. Age estimate of the N370S mutation causing Gaucher disease in Ashkenazi Jews and European populations: A reappraisal of haplotype data. American journal of human genetics 66, 692-697.

Cortés, A., Mellombo, M., Mgone, C.S., Beck, H.P., Reeder, J.C., Cooke, B.M., 2005. Adhesion of Plasmodium falciparum-infected red blood cells to CD36 under flow is enhanced by the cerebral malaria-protective trait South-East Asian ovalocytosis. Mol Biochem Parasitol 142, 252-257.

Cox, M.P., Nelson, M.G., Tumonggor, M.K., Ricaut, F.X., Sudoyo, H., 2012. A small cohort of Island Southeast Asian women founded Madagascar. Proceedings. Biological sciences / The Royal Society 279, 2761-2768.

Donohue, M., Denham, T., 2010. Farming and Language in Island Southeast Asia Reframing Austronesian History. Current Anthropology 51, 223-256.

Fay, J.C., Wu, C.I., 2000. Hitchhiking under positive Darwinian selection. Genetics 155, 1405-1413.

Fenner, J.N., 2005. Cross-cultural estimation of the human generation interval for use in genetics-based population divergence studies. American journal of physical anthropology 128, 415-423.

Fu, W., Akey, J.M., 2013. Selection and adaptation in the human genome. Annual review of genomics and human genetics 14, 467-489.

Fu, Y.X., Li, W.H., 1993. Statistical tests of neutrality of mutations. Genetics 133, 693709.

Genton, B., al-Yaman, F., Mgone, C.S., Alexander, N., Paniu, M.M., Alpers, M.P., Mokela, D., 1995. Ovalocytosis and cerebral malaria. Nature 378, 564-565.

Green, R.E., Krause, J., Briggs, A.W., Maricic, T., Stenzel, U., Kircher, M., Patterson, N., Li, H., Zhai, W., Fritz, M.H., Hansen, N.F., Durand, E.Y., Malaspinas, A.S., Jensen, J.D., Marques-Bonet, T., Alkan, C., Prufer, K., Meyer, M., Burbano, H.A., Good, J.M., Schultz, R., Aximu-Petri, A., Butthof, A., Hober, B., Hoffner, B., Siegemund, M., Weihmann, A., Nusbaum, C., Lander, E.S., Russ, C., Novod, N., Affourtit, J., Egholm, 
M., Verna, C., Rudan, P., Brajkovic, D., Kucan, Z., Gusic, I., Doronichev, V.B., Golovanova, L.V., Lalueza-Fox, C., de la Rasilla, M., Fortea, J., Rosas, A., Schmitz, R.W., Johnson, P.L., Eichler, E.E., Falush, D., Birney, E., Mullikin, J.C., Slatkin, M., Nielsen, R., Kelso, J., Lachmann, M., Reich, D., Paabo, S., 2010. A draft sequence of the Neandertal genome. Science 328, 710-722.

Guillot, E.G., Tumonggor, M.K., Lansing, J.S., Sudoyo, H., Cox, M.P., 2013. Climate Change Influenced Female Population Sizes through Time across the Indonesian Archipelago. Human Biology 85.

Hartl, D.L., 2004. The origin of malaria: mixed messages from genetic diversity. Nature reviews. Microbiology 2, 15-22.

Hedrick, P.W., 2012. Resistance to malaria in humans: the impact of strong, recent selection. Malaria journal 11, 349.

Hermisson, J., Pennings, P.S., 2005. Soft sweeps: molecular population genetics of adaptation from standing genetic variation. Genetics 169, 2335-2352.

Hudson, R.R., Kaplan, N.L., 1985. Statistical properties of the number of recombination events in the history of a sample of DNA sequences. Genetics 111, 147-164.

Jarolim, P., Palek, J., Amato, D., Hassan, K., Sapak, P., Nurse, G.T., Rubin, H.L., Zhai, S., Sahr, K.E., Liu, S.C., 1991. Deletion in erythrocyte band 3 gene in malaria-resistant Southeast Asian ovalocytosis. Proceedings of the National Academy of Sciences of the United States of America 88, 11022-11026.

Jones, B.L., Raga, T.O., Liebert, A., Zmarz, P., Bekele, E., Danielsen, E.T., Olsen, A.K., Bradman, N., Troelsen, J.T., Swallow, D.M., 2013. Diversity of lactase persistence alleles in Ethiopia: signature of a soft selective sweep. American journal of human genetics $93,538-544$.

Joy, D.A., Feng, X., Mu, J., Furuya, T., Chotivanich, K., Krettli, A.U., Ho, M., Wang, A., White, N.J., Suh, E., Beerli, P., Su, X.Z., 2003. Early origin and recent expansion of Plasmodium falciparum. Science 300, 318-321.

Kim, Y., Stephan, W., 2002. Detecting a local signature of genetic hitchhiking along a recombining chromosome. Genetics 160, 765-777.

Kimura, M., Shimizu, Y., Settheetham-Ishida, W., Soemantri, A., Tiwawech, D., Romphruk, A., Duangchan, P., Ishida, T., 1998. Twenty-seven base pair deletion in erythrocyte band 3 protein gene responsible for Southeast Asian ovalocytosis is not common among Southeast Asians. Hum Biol 70, 993-1000.

Kimura, M., Soemantri, A., Siswanto, J.E., Ishida, T., 2006. Ovalocytosis without band 3 gene 27-bp deletion and malaria infection. Anthropological Science 114, 161-164.

Kimura, M., Tamam, M., Soemantri, A., Nakazawa, M., Ataka, Y., Ohtsuka, R., Ishida, T., 2003. Distribution of a 27-bp deletion in the band 3 gene in South Pacific islanders. J Hum Genet 48, 642-645.

Kong, A., Thorleifsson, G., Gudbjartsson, D.F., Masson, G., Sigurdsson, A., Jonasdottir, A., Walters, G.B., Gylfason, A., Kristinsson, K.T., Gudjonsson, S.A., Frigge, M.L., 
Helgason, A., Thorsteinsdottir, U., Stefansson, K., 2010. Fine-scale recombination rate differences between sexes, populations and individuals. Nature 467, 1099-1103.

Laosombat, V., Dissaneevate, S., Wongchanchailert, M., Satayasevanaa, B., 2005. Neonatal anemia associated with Southeast Asian ovalocytosis. Int. J. Hematol. 82, 201-205.

Laosombat, V., Viprakasit, V., Dissaneevate, S., Leetanaporn, R., Chotsampancharoen, T., Wongchanchailert, M., Kodchawan, S., Thongnoppakun, W., Duangchu, S., 2010. Natural history of Southeast Asian Ovalocytosis during the first 3 years of life. Blood cells, molecules \& diseases 45, 29-32.

Librado, P., Rozas, J., 2009. DnaSP v5: a software for comprehensive analysis of DNA polymorphism data. Bioinformatics 25, 1451-1452.

Liu, S.C., Jarolim, P., Rubin, H.L., Palek, J., Amato, D., Hassan, K., Zaik, M., Sapak, P., 1994. The homozygous state for the band 3 protein mutation in Southeast Asian Ovalocytosis may be lethal. Blood 84, 3590-3591.

Liu, W., Li, Y., Shaw, K.S., Learn, G.H., Plenderleith, L.J., Malenke, J.A., Sundararaman, S.A., Ramirez, M.A., Crystal, P.A., Smith, A.G., Bibollet-Ruche, F., Ayouba, A., Locatelli, S., Esteban, A., Mouacha, F., Guichet, E., Butel, C., AhukaMundeke, S., Inogwabini, B.I., Ndjango, J.B., Speede, S., Sanz, C.M., Morgan, D.B., Gonder, M.K., Kranzusch, P.J., Walsh, P.D., Georgiev, A.V., Muller, M.N., Piel, A.K., Stewart, F.A., Wilson, M.L., Pusey, A.E., Cui, L., Wang, Z., Farnert, A., Sutherland, C.J., Nolder, D., Hart, J.A., Hart, T.B., Bertolani, P., Gillis, A., LeBreton, M., Tafon, B., Kiyang, J., Djoko, C.F., Schneider, B.S., Wolfe, N.D., Mpoudi-Ngole, E., Delaporte, E., Carter, R., Culleton, R.L., Shaw, G.M., Rayner, J.C., Peeters, M., Hahn, B.H., Sharp, P.M., 2014. African origin of the malaria parasite Plasmodium vivax. Nature communications 5, 3346.

Louicharoen, C., Patin, E., Paul, R., Nuchprayoon, I., Witoonpanich, B., Peerapittayamongkol, C., Casademont, I., Sura, T., Laird, N.M., Singhasivanon, P., Quintana-Murci, L., Sakuntabhai, A., 2009. Positively selected G6PD-Mahidol mutation reduces Plasmodium vivax density in Southeast Asians. Science 326, 1546-1549.

Maynard Smith, J., Haigh, J., 1974. The hitch-hiking effect of a favorable gene. Genet Res 23, 23-35.

Mgone, C.S., Koki, G., Paniu, M.M., Kono, J., Bhatia, K.K., Genton, B., Alexander, N.D., Alpers, M.P., 1996. Occurrence of the erythrocyte band 3 (AE1) gene deletion in relation to malaria endemicity in Papua New Guinea. Trans R Soc Trop Med Hyg 90, 228-231.

Mu, J., Duan, J., Makova, K.D., Joy, D.A., Huynh, C.Q., Branch, O.H., Li, W.H., Su, X.Z., 2002. Chromosome-wide SNPs reveal an ancient origin for Plasmodium falciparum. Nature 418, 323-326.

Müller, I., Bockarie, M., Alpers, M., Smith, T., 2003. The epidemiology of malaria in Papua New Guinea. Trends Parasitol 19, 253-259.

Myers, S., Bottolo, L., Freeman, C., McVean, G., Donnelly, P., 2005. A fine-scale map of recombination rates and hotspots across the human genome. Science 310, 321-324. 
Neafsey, D.E., Galinsky, K., Jiang, R.H., Young, L., Sykes, S.M., Saif, S., Gujja, S., Goldberg, J.M., Young, S., Zeng, Q., Chapman, S.B., Dash, A.P., Anvikar, A.R., Sutton, P.L., Birren, B.W., Escalante, A.A., Barnwell, J.W., Carlton, J.M., 2012. The malaria parasite Plasmodium vivax exhibits greater genetic diversity than Plasmodium falciparum. Nature genetics 44, 1046-1050.

Nei, M., 1987. Molecular Evolutionary Genetics. Columbia University Press, New York.

Nei, M., Li, W.H., 1979. Mathematical model for studying genetic variation in terms of restriction endonucleases. Proceedings of the National Academy of Sciences of the United States of America 76, 5269-5273.

Ngouprommin, L., Sae-ung, N., Fucharoen, S., Fucharoen, G., Sanchaisuriya, K., 2012. Prevalence of Southeast Asian Ovalocytosis in Thai Population. International Journal of Laboratory Hematology 34, 145-146.

O'Donnell, A., Allen, S.J., Mgone, C.S., Martinson, J.J., Clegg, J.B., Weatherall, D.J., 1998. Red cell morphology and malaria anaemia in children with Southeast-Asian ovalocytosis band 3 in Papua New Guinea. Br. J. Haematol. 101, 407-412.

Ohashi, J., Naka, I., Patarapotikul, J., Hananantachai, H., Brittenham, G., Looareesuwan, S., Clark, A.G., Tokunaga, K., 2004. Extended linkage disequilibrium surrounding the hemoglobin $E$ variant due to malarial selection. American journal of human genetics 74, 1198-1208.

Patel, S.S., Mehlotra, R.K., Kastens, W., Mgone, C.S., Kazura, J.W., Zimmerman, P.A., 2001. The association of the glycophorin $C$ exon 3 deletion with ovalocytosis and malaria susceptibility in the Wosera, Papua New Guinea. Blood 98, 3489-3491.

Peter, B.M., Huerta-Sanchez, E., Nielsen, R., 2012. Distinguishing between Selective Sweeps from Standing Variation and from a De Novo Mutation. Plos Genet 8.

Picard, V., Proust, A., Eveillard, M., Flatt, J.F., Couec, M.L., Caillaux, G., FeneantThibault, M., Finkelstein, A., Raphael, M., Delaunay, J., Bruce, L.J., Pissard, S., Thomas, C., 2014. Homozygous Southeast Asian ovalocytosis is a severe dyserythropoietic anemia associated with distal renal tubular acidosis. Blood 123, 19631965.

Pierron, D., Razafindrazaka, H., Pagani, L., Ricaut, F.X., Antao, T., Capredon, M., Sambo, C., Radimilahy, C., Rakotoarisoa, J.A., Blench, R.M., Letellier, T., Kivisild, T., 2014. Genome-wide evidence of Austronesian-Bantu admixture and cultural reversion in a hunter-gatherer group of Madagascar. Proceedings of the National Academy of Sciences of the United States of America 111, 936-941.

Poolsuwan, S., 1995. Malaria in prehistoric southeastern Asia. The Southeast Asian journal of tropical medicine and public health 26, 3-22.

Pritchard, J.K., Pickrell, J.K., Coop, G., 2010. The genetics of human adaptation: hard sweeps, soft sweeps, and polygenic adaptation. Current biology : CB 20, R208-215.

Przeworski, M., 2002. The signature of positive selection at randomly chosen loci. Genetics 160, 1179-1189. 
Przeworski, M., Coop, G., Wall, J.D., 2005. The signature of positive selection on standing genetic variation. Evolution; international journal of organic evolution 59, 23122323.

Rabe, T., Jambou, R., Rabarijaona, L., Raharimalala, L., Rason, M.A., Ariey, F., Dhermy, D., 2002. South-East Asian ovalocytosis among the population of the Highlands of Madagascar: a vestige of the island's settlement. Trans R Soc Trop Med Hyg 96, 143-144.

Reardon, D.M., Seymour, C.A., Cox, T.M., Pinder, J.C., Schofield, A.E., Tanner, M.J., 1993. Hereditary ovalocytosis with compensated haemolysis. Br. J. Haematol. 85, 197199.

Reich, D., Green, R.E., Kircher, M., Krause, J., Patterson, N., Durand, E.Y., Viola, B., Briggs, A.W., Stenzel, U., Johnson, P.L., Maricic, T., Good, J.M., Marques-Bonet, T., Alkan, C., Fu, Q., Mallick, S., Li, H., Meyer, M., Eichler, E.E., Stoneking, M., Richards, M., Talamo, S., Shunkov, M.V., Derevianko, A.P., Hublin, J.J., Kelso, J., Slatkin, M., Paabo, S., 2010. Genetic history of an archaic hominin group from Denisova Cave in Siberia. Nature 468, 1053-1060.

Risch, N., de Leon, D., Ozelius, L., Kramer, P., Almasy, L., Singer, B., Fahn, S., Breakefield, X., Bressman, S., 1995. Genetic analysis of idiopathic torsion dystonia in Ashkenazi Jews and their recent descent from a small founder population. Nature genetics 9, 152-159.

Rosanas-Urgell, A., Lin, E., Manning, L., Rarau, P., Laman, M., Senn, N., Grimberg, B.T., Tavul, L., Stanisic, D.I., Robinson, L.J., Aponte, J.J., Dabod, E., Reeder, J.C., Siba, P., Zimmerman, P.A., Davis, T.M., King, C.L., Michon, P., Mueller, I., 2012. Reduced risk of Plasmodium vivax malaria in Papua New Guinean children with Southeast Asian ovalocytosis in two cohorts and a case-control study. PLoS medicine 9, e1001305.

Schofield, A.E., Reardon, D.M., Tanner, M.J., 1992. Defective anion transport activity of the abnormal band 3 in hereditary ovalocytic red blood cells. Nature 355, 836-838.

Slatkin, M., 2008. A Bayesian method for jointly estimating allele age and selection intensity. Genetics research 90, 129-137.

Tajima, F., 1989. Statistical method for testing the neutral mutation hypothesis by DNA polymorphism. Genetics 123, 585-595.

Tanabe, K., Mita, T., Jombart, T., Eriksson, A., Horibe, S., Palacpac, N., RanfordCartwright, L., Sawai, H., Sakihama, N., Ohmae, H., Nakamura, M., Ferreira, M.U., Escalante, A.A., Prugnolle, F., Bjorkman, A., Farnert, A., Kaneko, A., Horii, T., Manica, A., Kishino, H., Balloux, F., 2010. Plasmodium falciparum accompanied the human expansion out of Africa. Current biology : CB 20, 1283-1289.

Tanner, M.J., Bruce, L., Martin, P.G., Rearden, D.M., Jones, G.L., 1991. Melanesian hereditary ovalocytes have a deletion in red cell band 3. Blood 78, 2785-2786.

Tsukahara, T., Hombhanje, F.W., Lum, J.K., Hwaihwanje, I., Masta, A., Kaneko, A., Kobayakawa, T., 2006. Austronesian origin of the 27-bp deletion of the erythrocyte band 
3 gene in East Sepik, Papua New Guinea inferred from mtDNA analysis. J Hum Genet 51, 244-248.

Vidyatilake, H.M., Gooneratne, L.V., 2004. Two families in Sri Lanka with Southeast Asian ovalocytosis. Ceylon Med. J. 49, 27-29.

Watterson, G.A., 1975. On the number of segregating sites in genetical models without recombination. Theor Popul Biol 7, 256-276.

Wilder, J.A., Stone, J.A., Preston, E.G., Finn, L.E., Ratcliffe, H.L., Sudoyo, H., 2009.

Molecular population genetics of SLC4A1 and Southeast Asian ovalocytosis. Journal of human genetics $54,182-187$. 
Figure 1

Polymorphic Site

Population

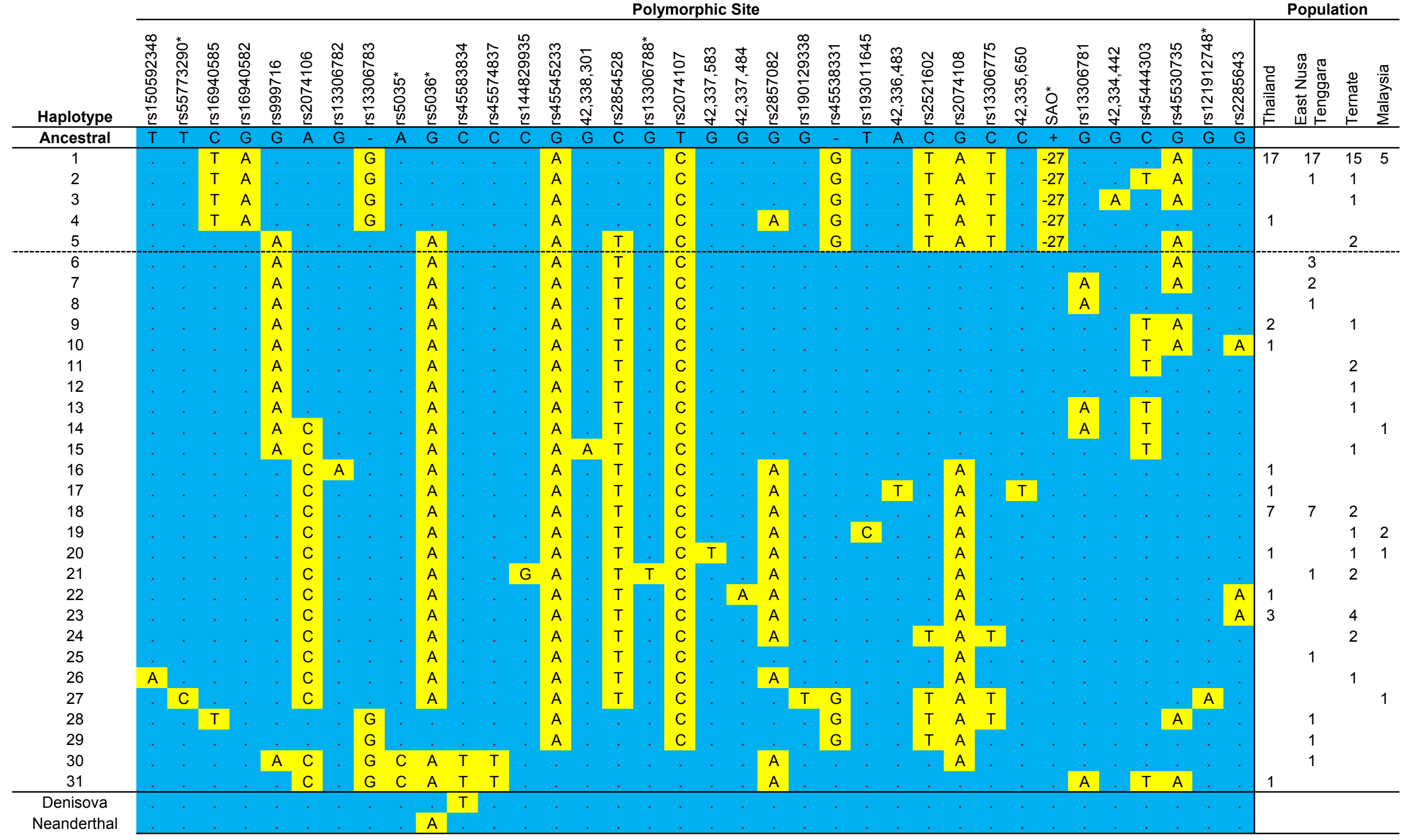


Figure 2

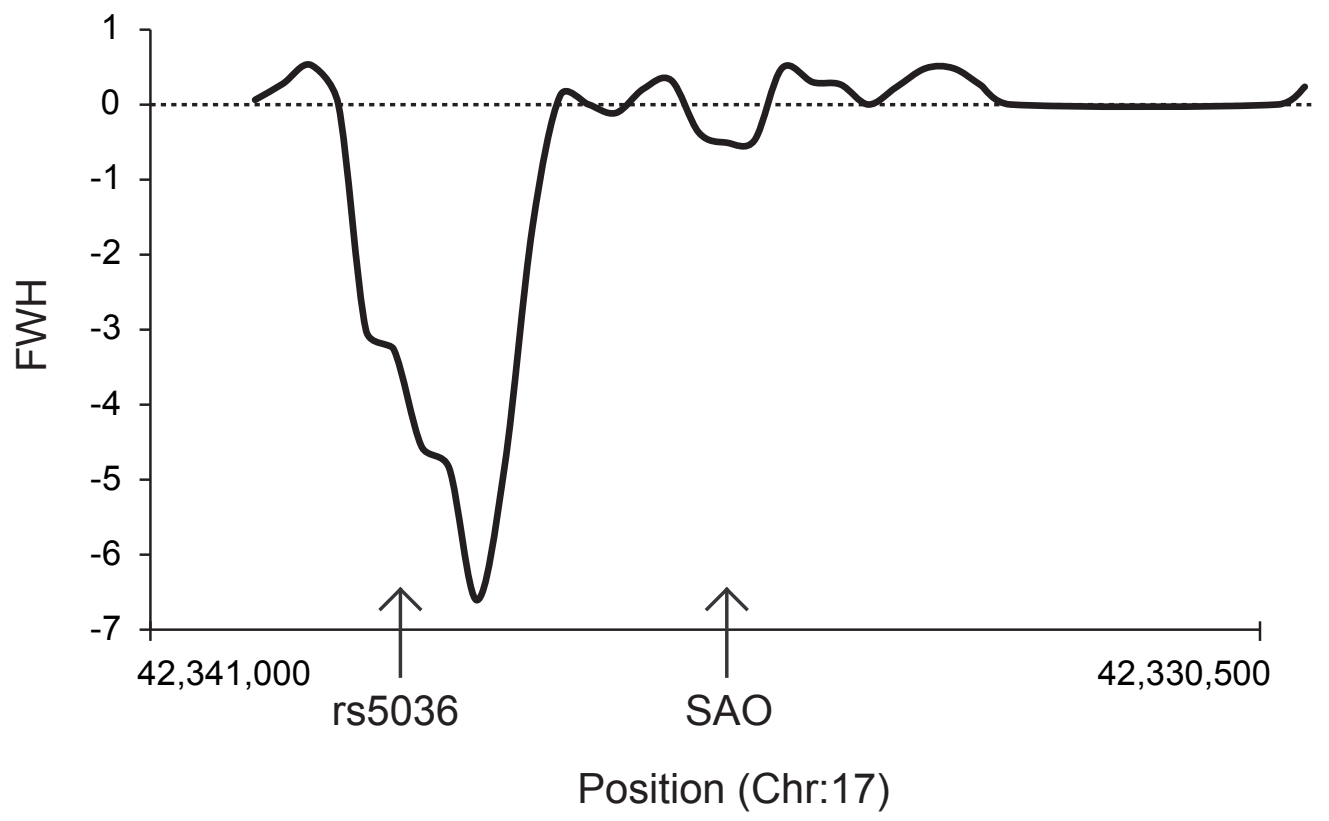


Figure 3

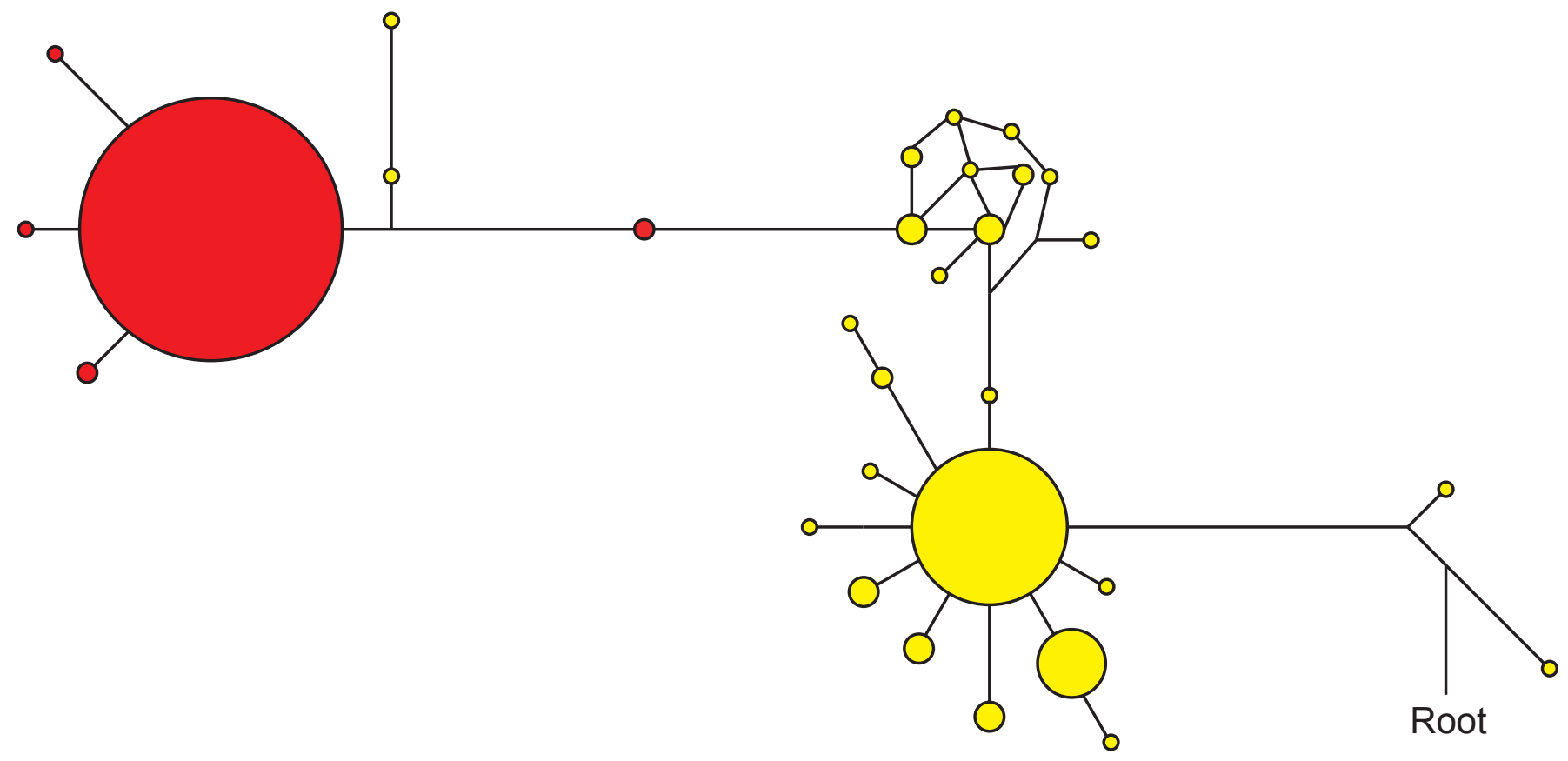


Figure 4

A.

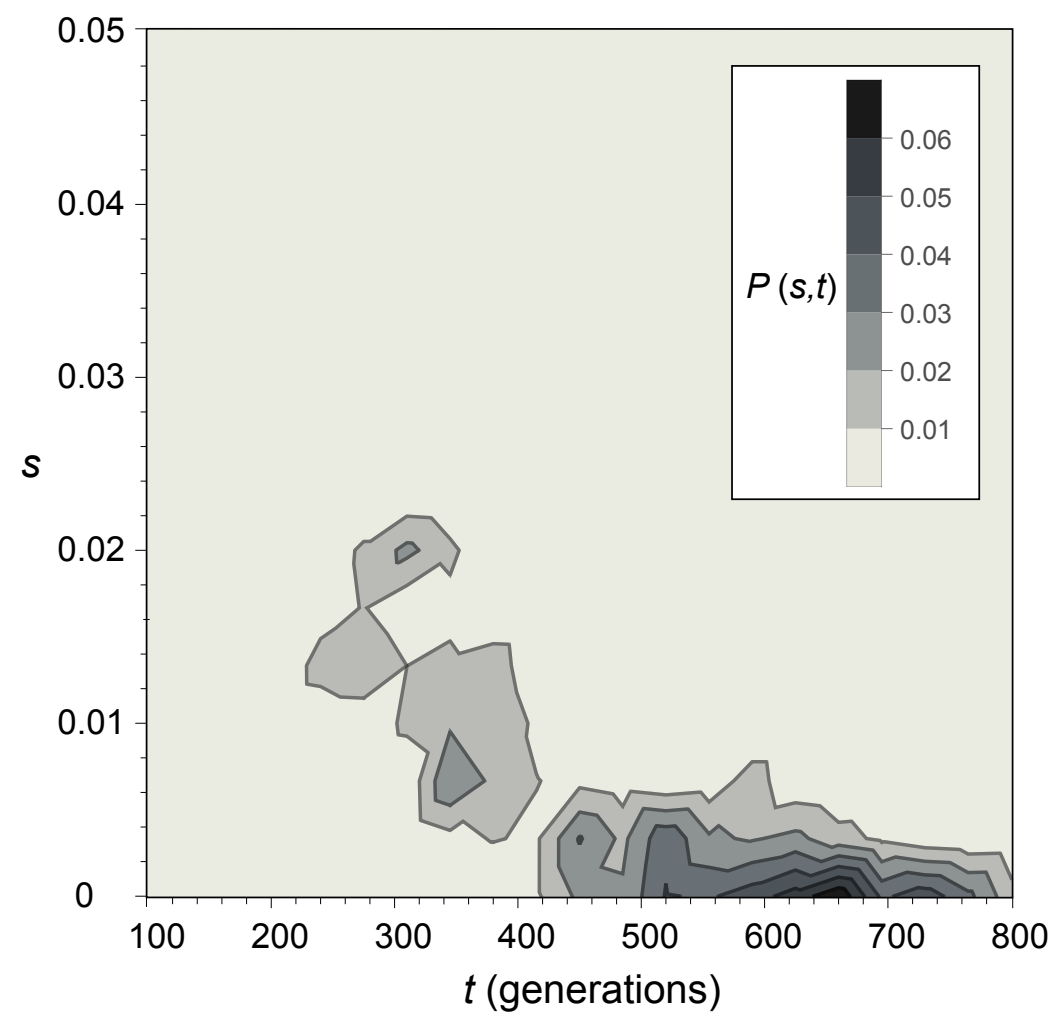

B.

C.
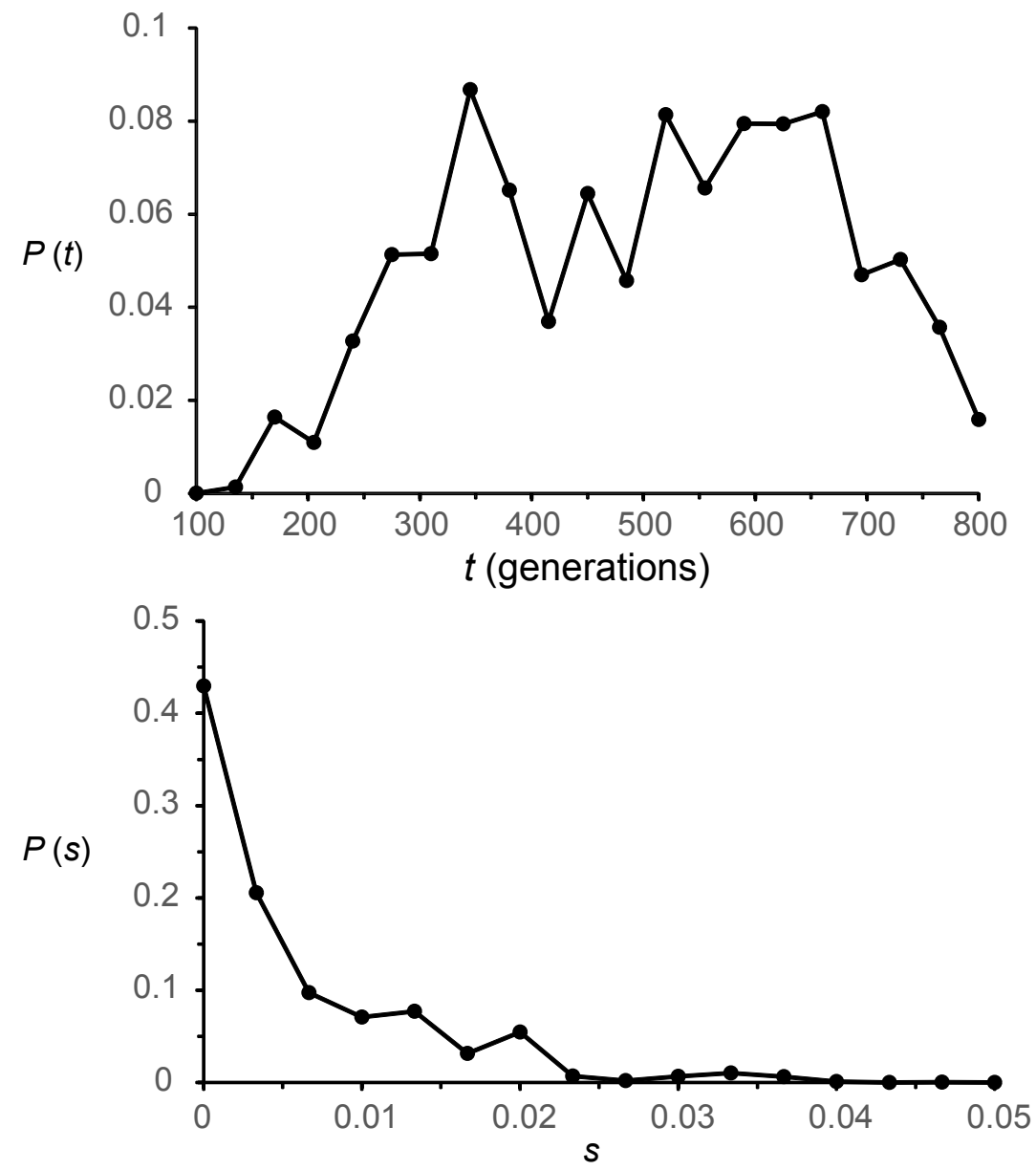